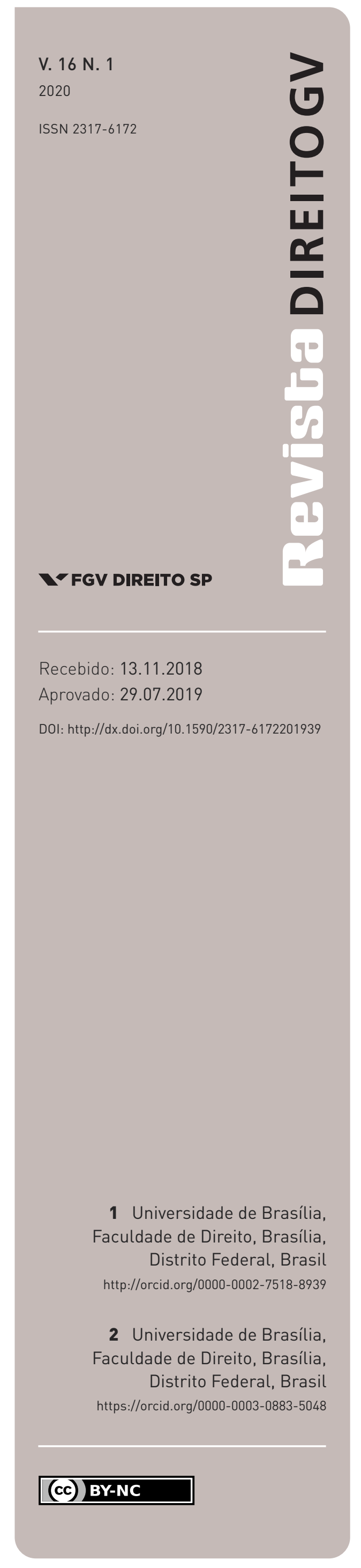

\section{Concepções genderizadas na análise de deferimento das Medidas Protetivas de Urgência (MPUs)}

\author{
GENDERIZED CONCEPTIONS IN THE ANALISYS OF PROTECTIVE ORDERS
}

\author{
Camila Cardoso de Mello Prando e Maria Paula Benjamim Borges ${ }^{2}$
}

\section{Resumo}

Este artigo aborda, sob o marco teórico da vitimologia feminista de Sandra Walklate, de gênero de Raewyn Connel e de stalking de Marlene Matos e Helena Grangeia, a maneira como as decisões judiciais operam o conceito de gênero em suas decisões associadas a casos de stalking, a partir das categorias de violência, risco e medo. Os objetos de análise foram oito Medidas Protetivas de Urgência (MPUs) indeferidas que passaram pela Defensoria Pública do Distrito Federal - Núcleo de Violência Doméstica e Familiar contra a Mulher, entre janeiro e julho de 2017, as quais apresentavam condutas de stalking. A partir da metodologia da análise de conteúdo, descobriu-se que os indeferimentos das MPUs se deram sob três vertentes: i) desconsideração das violências de gênero; ii) rejeição do medo da vítima como categoria legítima para se avaliar pedidos de MPUs; iii) baixa avaliação do risco para a segurança da vítima nos casos em que não se operam violências físicas.

\section{Palavras-chave}

Stalking; Medida Protetiva de Urgência; violência; risco; medo.

\section{Abstract}

This paper presents, under the premises of Sandra Walklate's feminist victimology, Raewyn Connel's gender theory, and Marlene Matos and Helena Grangeia's stalking definition, the ways by which judges conceive the concept of gender in their decisions when associated with stalking cases, through the categories of violence, risk and fear. The objects of analysis were eight denied restraining orders, which presented stalking behaviors, that litigated by the "Women's Protection Division" of the State Public Defender's Office, from January 2017 to July 2017. From the content analysis methodology, we discovered that there were three main arguments for the denials: i) gender violence unawareness; ii) rejection of the victim's fear as a legitimate category to evaluate the restraining orders' requests; iii) low risk evaluation for the victim's safety when there was no physical violence.

\section{Keywords}

Stalking; restraining order; violence; risk; fear. 


\section{INTRODUÇÃO}

Há cerca de 30 anos o termo stalking surgiu na literatura norte-americana para designar grupos de casos relacionados ao assédio persistente de homens contra mulheres com as quais haviam vivenciado a ruptura de um relacionamento, e que se traduzem em comportamentos de "perseguição, vigilância, monitorização, intimidação, ameaça ou outras formas de comunicação ou contacto, repetido e indesejado” (GRANGEIA e MATOS, 2010, p. 124). Esse termo passou a ser adotado em outros contextos de poder e a ser incorporado por alguns campos do sistema de justiça.

Neste artigo, pretendemos problematizar a intersecção entre casos identificados como stalking e o funcionamento do sistema de justiça criminal a partir de um grupo de casos presentes na avaliação da concessão de Medidas Protetivas de Urgência (MPUs) entre janeiro e julho de 2017 na circunscrição judiciária de Brasília. A fim de avaliarmos de que modo magistrados e magistradas organizam a ordem de gênero em suas decisões sobre a aplicação das MPUs, elegemos os conceitos de medo, risco e violência operados e interpretados nas decisões como referentes para a produção de análise de conteúdo das decisões selecionadas.

\section{A PERSPECTIVA PATOlOgizANTE dO CONCEITO DE STALKING NA LiTERATURA E A PROPOSTA DE UMA PERSPECTIVA FEMINISTA}

O stalking foi um termo cunhado inicialmente nos Estados Unidos para designar os fãs - em sua maioria homens que possuíam algum transtorno mental - que perseguiam e assediavam mulheres famosas (MULLEN et al., 1999). A expressão se tornou amplamente conhecida no país de língua inglesa depois da tentativa de homicídio da atriz Theresa Saldana, em 1982, do assassinato da atriz Rebecca Schaeffer, em 1988, e da perseguição à cantora Madonna, em 1995 (SAUNDERS, 1998). A partir de então, a perseguição insidiosa passou a ter importância relevante nos debates acadêmicos da área da psicologia, tendo em vista o alto índice de transtornos afetivos presentes nos pacientes que praticavam o stalking. Apenas posteriormente o assunto foi ter sua relevância demonstrada no âmbito jurídico, com a edição de leis de proteção às mulheres e de criminalização da conduta.

A literatura sobre stalking, predominantemente norte-americana, tem-se organizado em torno de cinco eixos: a identificação das características do homem que tem comportamentos identificados como stalking (ZONA et al., 1998; ROSENFELD, 2003), a identificação do conjunto de atos que configuram o stalking (MELOY, 1998; MULLEN, PATHÉ e PURCELL, 2000), os tipos de relações existentes entre as vítimas e os stalkers (HALL, 1998; PATHÉ e MULLEN, 1997), a compreensão do stalking como um preditor de risco de violências físicas (McFARLANE, CAMPBELL e WATSON, 2002; ROSENFELD, 2004; WALKER e MELOY, 1998) e o tratamento dos casos de stalking pelo sistema de justiça (JORDAN et al., 2003; TJADEN e THOENNES, 1998). 
Na maioria das pesquisas, os métodos de análise foram predominantemente quantitativos, e, com exceção do último eixo, o campo de análise se deu na psicologia forense. Seguindo uma tradição de pesquisas na intersecção sistema de justiça e psicologia norte-americana, as análises se fundaram em compreensões individualizantes e patologizantes do indivíduo identificado como stalker,${ }^{1}$ em delimitações sobre quantidade e qualidade de atos definidores do que se poderia chamar de stalking ${ }^{2}$ e na perspectiva de indicar o ato de stalking como um preditor de risco de violência, fundado na análise dos atos anteriores e do medo da vítima (ROSENFELD, 2004).

Tais perspectivas patologizantes e individualizantes, que se aproximam das simplificações do determinismo biológico e produzem vieses de pesquisa resultantes da falta de leitura estrutural que compreende os sujeitos situados em posições sociais e subjetivas diferenciadas, precisam ser ressignificadas a partir de teorias críticas, a fim de que seja possível tratar do tema sem reinscrever nele as formas de violência de gênero. Consequentemente, sob a perspectiva das pesquisas sobre sistema de justiça e direito penal, neste texto levamos em consideração os aspectos estruturais de gênero que informam conceitos como violência, risco

1 Walker e Meloy (1998) identificaram, no âmbito da violência doméstica, três tipos de ofensores: ofensores que buscavam poder e controle (power and control batterers), ofensores portadores de transtornos mentais (mentally ill batterers) e ofensores sociopatas criminais (criminal-psychopathic batterers). Mullen et al. (1999) classificaram os stalkers em: rejeitados (ofensores narcisistas), ressentidos (agressores que apresentam paranoia), em busca de intimidade (aqueles que possuem erotomania), cortejadores e predadores. Os stalkers rejeitados compreendem os ex-parceiros; os stalkers ressentidos são aqueles que por alguma razão sentem inimizade pela vítima; os stalkers em busca de intimidade e cortejadores são desconhecidos que buscam algum tipo de contato com a vítima; já os stalkers preadores são criminosos sexuais que perseguem a vítima para consecução do crime. Zona, Palarea e Lane (1998) classificaram os ofensores em: "simple obsessionals", "love obsessionals" e "erotomanic". O primeiro grupo engloba os stalkers que possuem algum tipo de relacionamento com a vítima. O segundo grupo enquadra aqueles sem nenhuma relação anterior com a vítima e que normalmente possuem esquizofrenia ou transtorno bipolar. No terceiro grupo se encontram os perseguidores com erotomania, que é a convicção delirante de que há uma pessoa secretamente apaixonada por ela.

2 Há muitas controvérsias na doutrina a respeito do conceito de stalking. Mullen et al. (1999) define stalking como uma conduta repetida (ao menos 10 vezes) e persistente (com duração mínima de 4 semanas) de aproximação ou contato tido pela vítima como indesejado. Por sua vez, Meloy (1998) aduz que o comportamento deve se dar por meio de ameaças implícitas ou explícitas, de forma maliciosa. Já McFarlane, Campbell e Watson (2002) afirmam que a conduta deve necessariamente gerar medo na vítima, levando em consideração o temor que uma pessoa média apresentaria. Tais requisitos limitam de tal forma o conceito de stalking que muitas condutas tipicamente persecutórias ficariam descaracterizadas. Os stalkers muitas vezes pretendem reatar o relacionamento, e por isso empregam meios não violentos nem ameaçadores (envio de cartas, flores e telefonemas). Há também os casos de pessoas que foram vítimas de perseguição sem nem ao menos saberem (foi o caso da atriz Theresa Saldana) e por isso não podem ter medo do comportamento. 
e medo na análise de acontecimentos de stalking, os quais são operados ao longo da judicialização dos casos de violência doméstica.

Com essa finalidade, ao longo do artigo optamos por dialogar com as referências teóricas sociais feministas (sobretudo com a teoria de Raewyn Connel) e da vitimologia feminista proposta por Sandra Walklate, a fim de ter como perspectiva estruturante a ordem de gênero na compreensão das dinâmicas de desigualdade e poder na relação entre vítima e autor nos contextos de violência doméstica.

Desse modo, partimos da definição abrangente de stalking proposta por Helena Grangeia e Marlene Matos (2010, p. 124): "padrão de comportamento de assédio persistente, traduzido em comportamentos de perseguição, vigilância, monitorização, intimidação, ameaça ou outras formas de comunicação ou contacto, repetido e indesejado", uma vez que sua delimitação não condiciona a ação a uma motivação individual e patologizante da parte do autor do stalking, nem demanda que a vítima sinta medo do comportamento. Essa definição é recolocada, no entanto, na perspectiva do stalking, como parte de uma ordem de gênero que leva em consideração as perspectivas feministas de vitimologia.

\section{DelimitaçÃo do CORPUS EMPÍRICO E MÉTODO DE ANÁliSE}

Para a realização da pesquisa foi feita uma parceria com a Defensoria Pública do Distrito Federal - Núcleo de Violência contra a Mulher de Brasília, para ter acesso aos processos de violência doméstica que tramitam na $1^{\mathrm{a}}, 2^{\mathrm{a}}$ e $3^{\mathrm{a}}$ Vara de Violência Doméstica de Brasília. As MPUs analisadas entre janeiro e julho de 2017 remetem a fatos ocorridos entre os anos de 2016 e 2017. Optou-se por uma amostragem por conveniência, portanto não foram investigados todos os processos nos quais a Defensoria Pública atuou entre janeiro e julho de 2017, mas tão somente uma parcela deles, que estava no núcleo nos dias em que uma das autoras deste artigo também estava presente. Assim, os dados não podem ser interpretados como amostra representativa, mas como corpus de análise de uma pesquisa qualitativa em profundidade.

O procedimento realizado se deu da seguinte forma: analisou-se o Boletim de Ocorrência (BO) que iniciou o processo de MPU; verificou-se se o relato da vítima condizia com um episódio de stalking, de acordo com o conceito de Grangeia e Matos (2010); apurou-se quais os delitos imputados ao autor pelo agente policial; e verificou-se se os pedidos de medidas protetivas foram deferidos ou não. Depois do procedimento inicial de levantamento de dados, foram analisados os argumentos que embasaram o indeferimento dos pedidos, como modo de compreender os discursos de gênero e de poder submersos nos textos, a partir da análise de conteúdo organizada em três eixos: medo, violência e risco. ${ }^{3}$

3 Análise de conteúdo é um "conjunto de técnicas de análise de comunicações”, um instrumento metodológico que tem como objeto qualquer tipo de discurso, desde o sociológico até o político e o jurídico. 
$\mathrm{Na}$ fase quantitativa da pesquisa, foram analisados 274 processos. Entre eles, 80 BOs relatam casos de stalking (29,2\%). Dos 80 processos que contêm episódios de stalking, 42 ações contidas no BO foram classificadas como contravenção penal de perturbação da tranquilidade (art. 65 do Decreto-Lei n. 3.688/1941); ${ }^{4} 3$ foram classificadas como contravenção penal de perturbação do trabalho ou do sossego alheio (art. 42 do Decreto-Lei

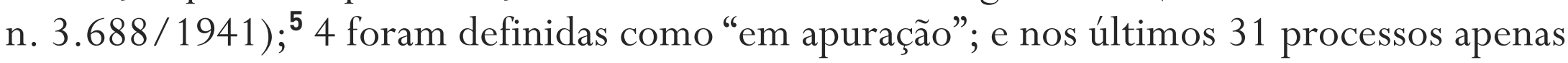
constavam os outros delitos praticados concomitantemente à perseguição, como ameaça, injúria, difamação, lesão corporal, vias de fato e dano ${ }^{6}$ (ver Gráfico 1, a seguir).

\section{GRÁFICO 1 - TIPIFICAÇÃO PENAL}

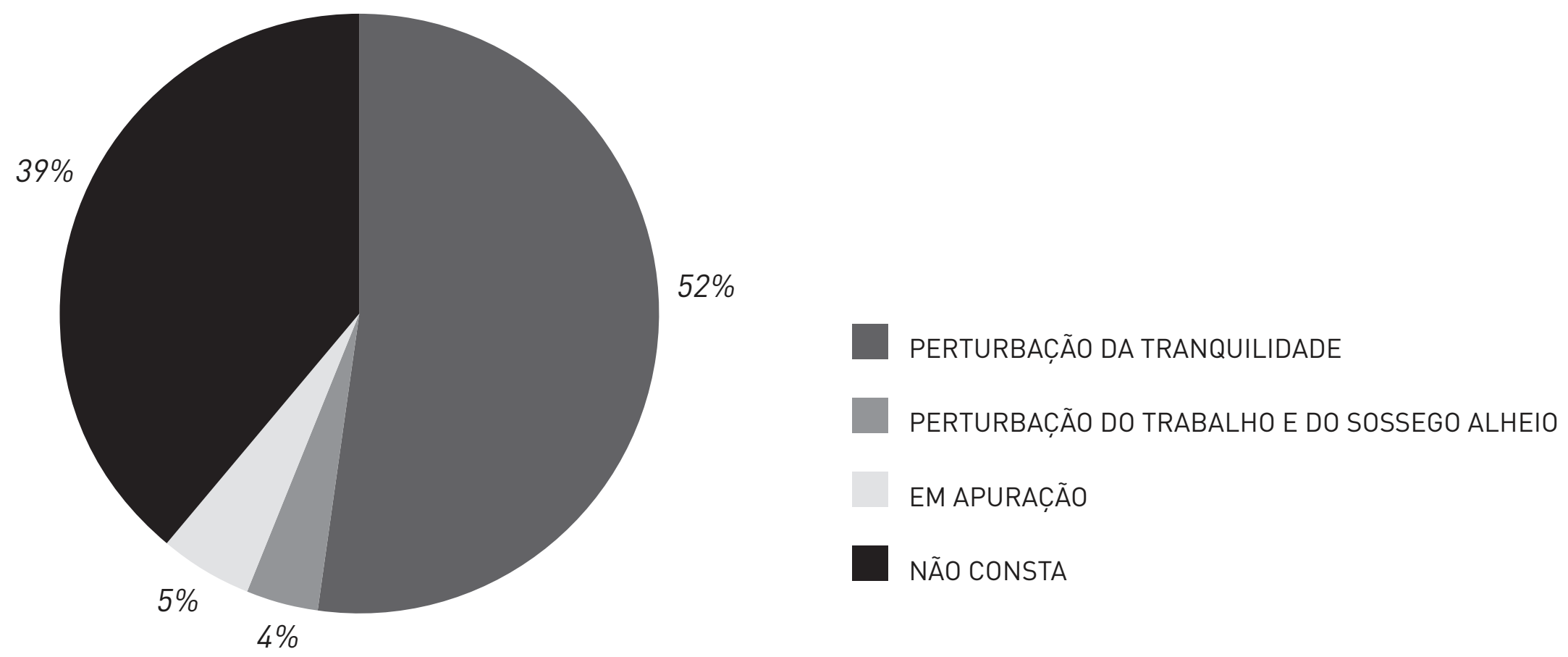

Fonte: Elaboração das autoras.

A análise de conteúdo busca compreender uma mensagem não dita no texto a partir de suas estruturas, seus significados e seus significantes, por meio de uma interpretação sistemática e objetiva da subjetividade do discurso (BARDIN, 1977).

4 "Art. 65. Molestar alguém ou perturbar-lhe a tranquilidade, por acinte ou por motivo reprovável: Pena - prisão simples, de quinze dias a dois meses, ou multa, de duzentos mil réis a dois contos de réis.”.

5 "Art. 42. Perturbar alguém o trabalho ou o sossego alheios:

I - com gritaria ou algazarra;

II - exercendo profissão incômoda ou ruidosa, em desacordo com as prescrições legais;

III - abusando de instrumentos sonoros ou sinais acústicos;

IV - provocando ou não procurando impedir barulho produzido por animal de que tem a guarda:

Pena - prisão simples, de quinze dias a três meses, ou multa, de duzentos mil réis a dois contos de réis.”.

6 O ordenamento jurídico pátrio não criminaliza a conduta do stalking. 
$\mathrm{Na}$ análise dos deferimentos e indeferimentos dos pedidos, os processos foram separados em três grupos: aqueles em que se imputava a prática de perturbação da tranquilidade/perturbação do trabalho ou do sossego alheio e outros crimes (Grupo 01); os que imputavam apenas perturbação da tranquilidade/perturbação do trabalho ou do sossego alheio (Grupo 02); e os que imputavam crimes diversos, sem perturbação da tranquilidade/perturbação do trabalho ou do sossego alheio (Grupo 03). No primeiro grupo, 30 MPUs foram deferidas e 4 foram indeferidas. No segundo grupo, 8 foram deferidas e 3, indeferidas. No último grupo, 31 pedidos foram deferidos e 4 , indeferidos. Assim, dos 80 processos de stalking analisados, 11 foram indeferidos por razões diversas. Dos 11 processos com MPUs indeferidas, 2 estão em segredo de justiça e 1 está arquivado no acervo geral, o que impossibilitou o acesso aos autos no segundo momento da pesquisa, da análise de conteúdo desses processos.

O objetivo da separação dos processos em grupos era avaliar se havia diferenciação entre o índice de deferimentos e indeferimentos entre os processos tipificados apenas como contravenção penal de perturbação da tranquilidade, apenas outros delitos e perturbação da tranquilidade em conjunto com outros delitos. Nos processos em que se imputava apenas a contravenção de perturbação de tranquilidade, a taxa de indeferimento de MPU foi maior que nos outros grupos (ver Gráficos 2, 3 e 4, a seguir).

GRÁFICO 2 - ÍNDICE DE INDEFERIMENTOS DO GRUPO OI : PERTURBAÇ̃̃O DA TRANQUILIDADE E OUTROS DELITOS

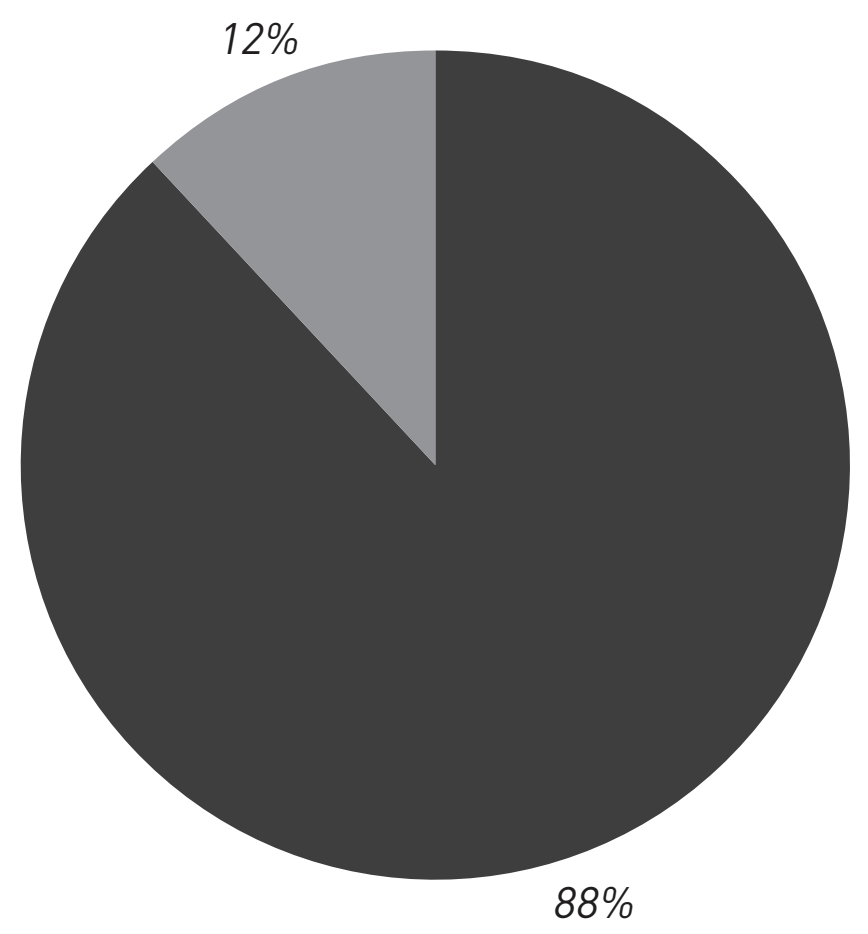

DEFERIDAS

INDEFERIDAS

Fonte: Elaboração das autoras. 
GRÁFICO 3 - ÍNDICE DE INDEFERIMENTOS DO GRUPO O2: APENAS PERTURBAÇÃO DA TRANQUILIDADE

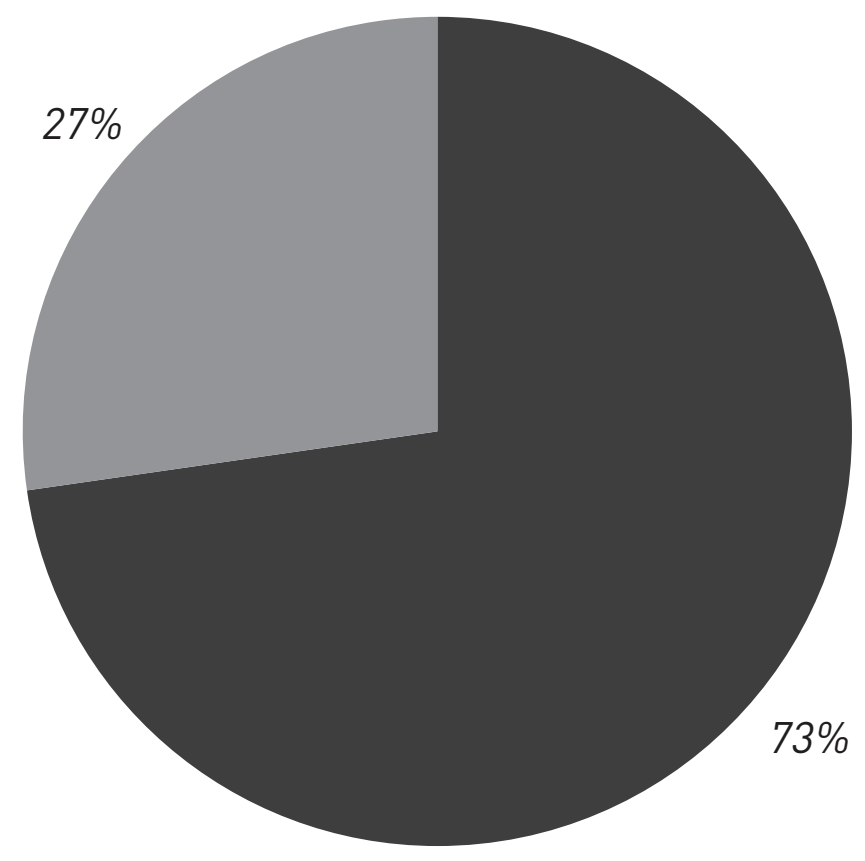

DEFERIDAS

INDEFERIDAS

Fonte: Elaboração das autoras.

GRÁFICO 4 - ÍNDICE DE INDEFERIMENTOS DO GRUPO 03: APENAS OUTROS DELITOS

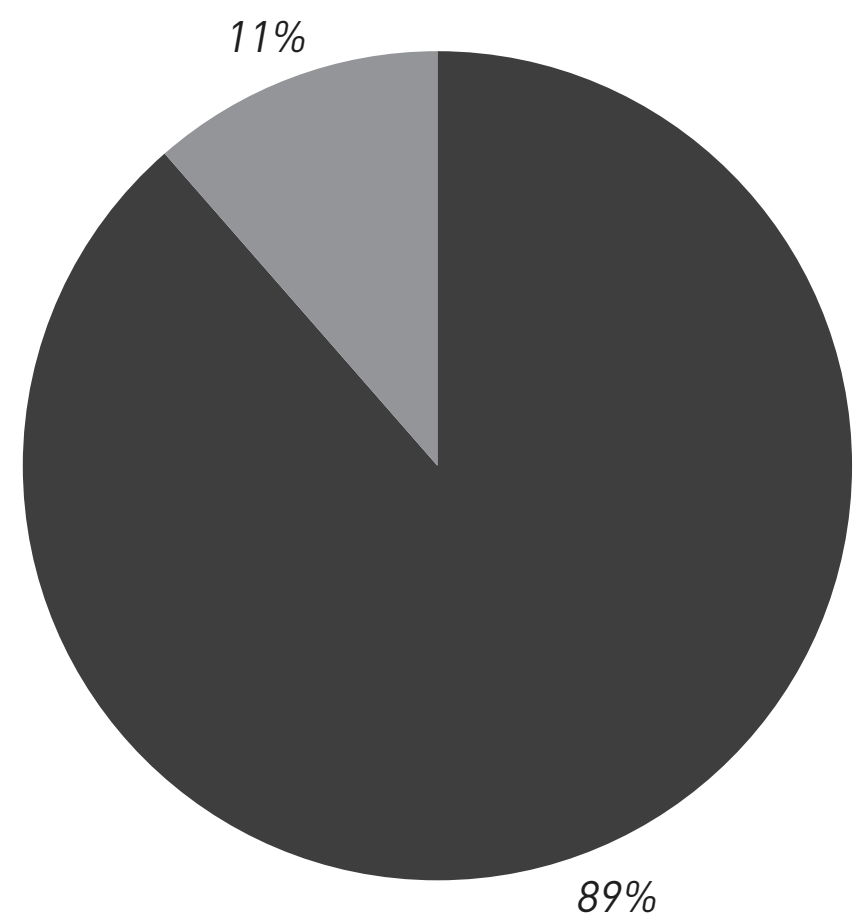

DEFERIDAS

INDEFERIDAS

Fonte: Elaboração das autoras. 
Embora nosso objetivo neste artigo não seja a produção de dados quantitativos de uma amostra representativa, tais resultados sobre o número de MPUs deferidas/indeferidas podem abrir pistas a pesquisas futuras sobre como se percebe o risco nos casos de práticas de stalking. Verifica-se que, nos casos em que apenas práticas de stalking são identificadas, não estando associadas a outras práticas definidas como delito, tais como lesão corporal e ameaça, a compreensão da existência de uma situação de risco para a integridade física e de violação da integridade psíquica da vítima parece diminuir.

Seguindo a literatura já produzida, essa pista se reforça nos trabalhos de Jordan et al. (2003) e Rosenfeld (2004). Jordan et al. (2003), em uma pesquisa com processos judiciais em Kentucky, nos Estados Unidos, perceberam que a maioria dos casos de stalking eram levados à justiça como contravenções penais e não como crimes. Da mesma maneira, Rosenfeld (2004) afirma que, quando um delito mais grave é cometido concomitantemente ao stalking, a perseguição fica invisibilizada pela atenção que se dá à conduta violenta, como se o stalking fosse englobado pela lesão corporal ou pela ameaça, não restando a violência psicológica caracterizada como danosa em si.

Em um segundo momento da pesquisa, delimitamos a análise de conteúdo dos 8 casos de indeferimento de MPUs com processos com possibilidade de acesso. Nosso objetivo era compreender em profundidade quais os sentidos de violência, medo e risco que informaram tais decisões de indeferimento, a fim de analisá-los criticamente, a partir da teoria social de gênero de Connel e da vitimologia feminista de Walklate. Com isso pretendemos observar de que modo a ordem de gênero organizou esses acontecimentos processuais. A Tabela 1, a seguir, sistematiza as descobertas.

TABELA 1 - FUNDAMENTOS DOS INDEFERIMENTOS DE MPUS

FUNDAMENTAÇÃO

DESCONSIDERAÇÃO DAS VIOLÊNCIAS DE GÊNERO

REJEIÇÃO DO MEDO

ANÁLISE DO RISCO

\section{PROCESSOS}

$4 \mathrm{E} 5$

$7 \mathrm{E} 8$

$2 \mathrm{E} 6$

Fonte: Elaboração das autoras. 


\section{VIOLÊNCIA}

As práticas de stalking estão organizadas em torno da produção de uma violência psicológica reiterada, considerando-se as perseguições, os monitoramentos, as mensagens e ligações indesejadas, ainda quando não acompanhadas de ameaças expressas ou agressões físicas. No entanto, ainda que a violência psicológica esteja descrita na Lei Maria da Penha (LMP) como uma forma de violência contra a mulher, Prando (2016) reconhece que, por não deixar vestígios nem marcas externas, não é reconhecida como violência de fato.

Nas decisões de indeferimento das MPUs, constatou-se uma negação das dimensões das violências de gênero não associadas diretamente a violências físicas e não subsumidas a um tipo penal de crime, especialmente quando as violências se manifestavam em suas dimensões psicológica e patrimonial nos processos identificados unicamente com as contravenções penais. As disputas ocorridas no espaço eram invisibilizadas quando se organizavam em torno de questões patrimoniais e psicológicas, submetendo, assim, o deferimento da MPU a uma cognição criminal, em desacordo com o dispositivo do art. 22 da LMP, que prevê como fundamento da MPU a "prática de violência doméstica e familiar contra a mulher, nos termos desta Lei".

No Processo 04, a requerente informou que, depois de idas e vindas no relacionamento, com relatos de violência psicológica ("na interpretação da ofendida tais atitudes se tratavam de assédio psicológico conhecido como gaslighting””), moral e patrimonial, já tendo sido vítima de stalking por meio de redes sociais, o ex-companheiro teria invadido sua residência para furtar um documento de confissão de dívida que assinou em benefício dela. Nos pedidos de MPU, requereu que o sujeito devolvesse o documento a ela, bem como solicitou as outras medidas cautelares de afastamento. O magistrado indeferiu o pedido sob a alegação de que medidas protetivas "servem para preservar a integridade física e psicológica da mulher" $\mathrm{e}$ não para realizar cobrança de dívidas, ignorando dessa forma as práticas de perseguição geradoras de medo, alegado pela mulher, e de disputa patrimonial.

Por outro lado, em alguns dos indeferimentos identificamos a invisibilidade não apenas de alguns tipos de violência de gênero, tais como a violência psicológica, mas do próprio enquadramento de uma dimensão de gênero no conflito levado ao Juizado. No Processo 05, no qual figuravam como partes a enteada e o ex-padrasto, a vítima relata que descobriu uma

$7 \quad$ Gaslighting é uma forma de abuso psicológico em que o agressor nega fatos que ocorreram, banaliza o sentimento da vítima ou cria situações imaginárias para controlar a outra pessoa, de forma que a vítima passa a duvidar dos seus sentimentos e da sua sanidade, mantendo-se, assim, mais próxima e mais dependente do ofensor.

8 Embora não seja objetivo do artigo fazer uma análise corretiva das decisões analisadas, é importante frisar que a sentença citada não apenas reproduz invisibilidade de gênero, mas também viola as previsões legais da LMP, em seus artigos 18 , parágrafo $3^{\circ}$, e 24. 
traição à sua mãe pelo ex-padrasto e que relatou o fato à genitora, que preferiu acabar com o relacionamento. Como a vítima e o ofensor trabalhavam no mesmo local, ela no período da noite e ele no período da manhã, o ex-padrasto passou a ameaçá-la constantemente quando se encontravam nos momentos de mudança de turno, chegando a afirmar: "Então você quer me peitar?! Quer me peitar?! Quer dizer que eu não posso fazer nada, que sou um mero encarregado?! Pode deixar, eu vou te mostrar o poder que eu tenho, você está enganada!”.

O magistrado indeferiu o pedido de MPU sob a fundamentação de que não havia motivação de gênero na disputa, pois as condutas imputadas ao requerido se deram pelo fato de que a vítima contribuiu para o fim da relação do ofensor com a genitora da requerente e não por sua condição de mulher. Connel (2015) identifica as práticas sociais fundadas na ordem de gênero em quatro dimensões: poder, produção, catexia e simbolismo. ${ }^{9}$ É justo na dimensão do poder que localizamos o conflito descrito anteriormente, na medida em que ele se organiza a partir de uma relação de dominação e de suposição de direito à dominação pela parte do padrasto. A sua fala ressalta seu temor em perder a autoridade e o controle que antes tinha no relacionamento. Nos moldes do conceito de gênero apresentado por Connel, ele era o sujeito que mandava, que dominava e que era influente. Percebe-se, ademais, que seu alcance direto sobre a companheira foi extinto e deslocado para a enteada, visando submetê-la à sua influência.

Nesse sentido, constata-se a conduta realizada em um contexto de ordem de gênero, capaz de atrair a incidência da LMP. De fato, a Exposição de Motivos da Lei n. 11.340/2006 aduz que: "a violência intrafamiliar expressa dinâmicas de poder e afeto, nas quais estão presentes relações de subordinação e dominação [...]. Um sistema de dominação passa a considerar natural uma desigualdade socialmente construída”. A própria legislação se baseia na identificação de relacionamentos hierarquicamente posicionados, independentemente dos múltiplos motivos do agente no momento da ação.

Tanto no exemplo do primeiro caso quanto do último aqui apresentado, observamos, nos indeferimentos das MPUs, uma invisibilidade (gender blindness) nos sentidos atribuídos ao que é violento e que está fundado em uma relação de desigualdade de gênero. Tal sentido parece assentar-se em uma perspectiva hegemônica de violência fundada nas práticas de agressão entre homens no espaço público, em detrimento das relações afetivas domésticas dos casos em questão, que têm um sentido de continuidade e são baseadas em posições sociais gendrificadas.

9 Um exemplo de manifestação do poder seriam as recomendações de promoção de homens por homens, em empresas geridas por homens e para homens; um exemplo de acumulação de capital seria a diferença de remuneração entre homens e mulheres; a representação da catexia seria a impossibilidade/negação de formação de um vínculo emocional por meio do sexo; um exemplo do simbolismo é o masculino universal. 


\section{MEDO}

Nas decisões de indeferimento também restou evidenciada uma invisibilidade da gendrificação dos sentidos do medo, alinhada aos sentidos hegemônicos de violência exemplificados anteriormente. O medo é posto como reação irracional às investidas dos ofensores, ocultando-se as disputas de poder e de imposições de controle da vida do outro. Tem-se que as interpretações das relações entre a vítima e o agressor e as concepções do medo são "gender-blind" (termo utilizado por Walklate para explicar como a experiência do universal é masculina e ignora as relações assimétricas de gênero).

No Processo 07, a vítima informou que já havia registrado inúmeros BOs contra o ex-companheiro. O último deles gerou uma MPU, que se encerrou logo antes dos fatos narrados na presente ocorrência. A requerente depôs que acredita que o ex-companheiro a vigia, porque, logo depois do encerramento das medidas protetivas, ele a abordou na rua afirmando: "você sabia que se eu te pegar com outro homem eu vou te matar e você sabe que eu estou de olho em você. Você não vai ser minha também não vai ser de ninguém”. Logo após esse fato, a requerente foi deixar a filha na escola, momento em que o ofensor novamente apareceu ameaçando-a nos mesmos termos, o que continuou ao longo do dia. Depois do aditamento do $\mathrm{BO}$, a vítima relatou que o requerido passou a mandar diversas mensagens ameaçadoras para ela, afirmando que queria reatar o relacionamento.

O magistrado indeferiu o pedido afirmando que a intenção do ofensor seria apenas encontrar com a requerente para conversar. E afirmou que, se esta estivesse insatisfeita, deveria promover o bloqueio do número do requerido para não receber mais mensagens. Em sua decisão, o juiz implicitamente afirma que a mulher não deveria temer as atitudes do ofensor, tendo em vista que sua intenção era meramente aproximar-se da requerente.

No Processo 08, a vítima informou que o requerido tinha horário de visitas fixo para se encontrar com o filho, mas que o ex-companheiro utilizava o pretexto de encontrar o menino para controlar a vida da vítima, ligando para ela a todo momento, passando em frente da casa dela fingindo que está falando ao telefone e fazendo visitas em horários não previamente combinados. Relatou, inclusive, que o requerido já descumpriu medidas protetivas anteriormente.

O juiz indeferiu o pedido de MPU sob o fundamento de que não foi comprovada a ocorrência da contravenção penal de perturbação da tranquilidade pela ausência da elementar do tipo "acinte ou motivo reprovável", tendo em vista que a razão pela qual o requerido busca contato com a vítima é a vontade de ver o filho, o que não demonstra aparente perigo à sua segurança. Além disso, afirmou que a vítima tinha consentido com as visitas diárias à sua residência. Constata-se a negação do medo em face de uma pessoa próxima, que frequenta a residência, que quer acompanhar a vida do filho e, por isso, não deveria gerar temor.

Percebe-se que, em ambas as situações em que o medo da vítima foi rejeitado, os homens estavam buscando contato indesejado com suas respectivas ex-companheiras, com contornos 
de reproprietização da mulher. Em um, o ofensor perseguia a companheira com o intuito de retomar o relacionamento, afirmando que a mataria se a visse com outro homem, confirmando a objetificação da mulher como sua propriedade. No outro, o autor passava em frente da casa da vítima com o intuito de vigiá-la, ao mesmo tempo em que fazia visitas ao filho fora dos horários marcados, também em um processo de proprietização do outro - da residência do outro, do horário do outro, do tempo do outro, do corpo do outro.

Nos dois processos em que o magistrado entende as atitudes do homem como legítimas e inócuas, fica implícita a percepção de que o medo da vítima é irracional diante dos comportamentos apresentados. Esse pensamento remete à teoria da criminologia administrativa, criada no século XIX, que, além de pregar que o medo do crime era irracional, também aduzia que as pessoas apenas não tinham conhecimento a respeito da realidade criminosa (traduzida aqui como a verdadeira realidade da violência de gênero no âmbito doméstico) (WALKLATE, 2004).

Essa teoria se baseia em uma visão positivista, de controle da natureza (controle do crime/ controle da mulher, que é o outro), que desde Auguste Comte (1978) prioriza a racionalidade, a objetividade e o método científico em detrimento da intuição, há muito vista como uma característica biológica da mulher e da experiência feminina (WALKLATE, 2004). A criminologia administrativa (e o sistema de justiça, como assinalado neste artigo) utiliza uma visão masculina do conhecimento (tomando por base as experiências do medo e do crime masculinos), que também pode ser visualizada nas decisões que negam a experiência do medo como experiência legítima da mulher.

Conforme explicitado por Walklate (2004), o medo é genderizado. Condutas iguais podem gerar medo em uma mulher e não gerar medo em um homem, ainda mais em um contexto de violência doméstica, em que o amor e o temor se encontram em conflito. As experiências de agressões sofridas ao longo de um relacionamento passado podem prever violências futuras, e o medo decorre dessas experiências pessoais. O ciclo da violência, quando percebido pela mulher, faz que se reconheçam as diversas violações sofridas, ainda que para um terceiro elas possam parecer simples declarações de amor, de modo que as experiências de violência e de medo são múltiplas e não podem ser compreendidas apenas a partir das experiências das violências patrimoniais e físicas de rua, que tendem a ser lidas pelo sistema de justiça como universais.

\section{RISCO}

Ao analisarmos o conteúdo das decisões no que se refere aos sentidos atribuídos ao conceito de risco, também reconhecemos a sua relação com as invisibilidades produzidas nos sentidos de violência e medo apresentadas nos itens anteriores. De fato, a análise do risco é subutilizada quando as violências perpetradas são psicológicas e lidas a partir de um contexto de violência de rua, em detrimento da violência em âmbito doméstico. Fundamenta-se uma 
avaliação do risco alta no âmbito público na comparação com o âmbito privado, das relações domésticas e familiares, em que o risco é considerado praticamente inexistente. Assim, quando esse risco chega a ser ponderado, ele o é de modo a atribuir o masculino como universal, afastando uma leitura qualificada pelas relações assimétricas de gênero - o risco é ponderado, portanto, por meio de uma “ocultação de gênero" [“gender-blind”].

No Processo 02, a vítima relatou que o ex-marido “não aceitava a separação", ligando para ela constante e insistentemente, até 18 vezes no mesmo dia, inclusive em horários inoportunos (de madrugada). A vítima informou que o ofensor também praticava alienação parental com os filhos, com o intuito de chantagear a vítima para reatar o casamento. $\mathrm{O}$ indeferimento da MPU foi motivado pela ausência de prova de uma situação de risco para a vítima.

No Processo 06, a vítima informou que é casada com o agressor há 24 anos e que moram na mesma residência. Relatou que o companheiro é uma pessoa agressiva e que costumeiramente a ofende em sua moral e destrói seus objetos pessoais. A requerente apontou outros BOs que já registrou contra o companheiro, e noticiou que, em determinada oportunidade, o ofensor foi até o seu trabalho, passou a xingá-la, afirmando que ela aprenderia a respeitá-lo, enquanto jogava sua touca no chão. Dias depois, após ingerir bebidas alcoólicas, o requerido, ao entrar na residência do casal, passou a ofender a vítima com xingamentos, jogou suas roupas no chão e arremessou uma cadeira no carro da requerente, momento em que passou a correr atrás da vítima dizendo que a pegaria.

O magistrado indeferiu o pedido tendo em vista que a ausência de provas impossibilita a aplicação da medida protetiva de afastamento do lar, por ser medida das mais críticas, e que, por sua vez, o indeferimento do afastamento do lar impossibilita o acolhimento das demais medidas pleiteadas, como proibição de comunicação e contato. Tal fundamentação remete a uma ideia de dicotomia entre a esfera pública e a privada, no sentido de reconhecer um risco à segurança da vítima apenas em casos de violências ocorridas fora do âmbito doméstico, partindo do pressuposto de que a residência seja um local seguro e inviolável. No caso, ponderou-se dois direitos aparentemente equilibrados (sem relações de poder), prevalecendo o direito do homem de ir e vir (transitando entre as duas esferas) em detrimento do direito da mulher de ter sua segurança garantida (mantendo a residência afastada da tutela do Estado).

Apesar da avaliação apriorística de inexistência de risco que fundamentou a não determinação de MPUs, a literatura tem associado as práticas de stalking como parte de um processo de espiral de agressões. Uma pesquisa realizada por Célia Ferreira e Marlene Matos, em 2013, em Portugal, com 104 mulheres que conviviam com o autor das agressões e foram vítimas de violência doméstica durante o relacionamento, descobriu que em 54\% dos episódios de stalking a vítima foi agredida fisicamente; em 37\% dos casos houve ameaça com arma ou outro objeto intimidador; em 35\% dos relatos houve contato sexual forçado; e em 29\% dos episódios houve tentativa de homicídio.

Em ambos os casos, seja por meio de agressões físicas, seja de ligações indesejadas, Rosenfeld (2004) entendeu que a ocorrência de ameaça em casos de stalking é um preditor de risco 
para a vítima, da mesma maneira que um relacionamento amoroso anterior à perseguição (PATHÉ e MULLEN, 1997). Tjaden e Thoennes (1998) também concluíram que os stalkers que eram ex-parceiros das vítimas foram significativamente mais abusivos nos relacionamentos anteriores do que os parceiros que não cometeram a perseguição. Ademais, constatou-se que as vítimas de stalking também sofreram outras violências psicológicas, morais e financeiras ao longo do relacionamento abusivo.

As contribuições feministas para as teorias do risco buscam ultrapassar a dicotomia público/privado ao reconhecer que muitas mulheres são vítimas de violência doméstica e que para elas a casa não é um ambiente seguro. A relutância em intervir no âmbito privado/doméstico das relações remete a um ideal de intervenção mínima que não reconhece relações assimétricas de poder. Tal afirmativa é consubstanciada nas fundamentações de indeferimento de MPUs em que se negam violências de gênero, especialmente aquelas vividas por mulheres vítimas de violência doméstica, e avaliam o risco por uma perspectiva masculinizada, sem levar em consideração as diversas formas de manter controle e poder sobre a mulher em contextos de desigualdade de gênero.

\section{CONSIDERAÇÕES FINAIS}

A compreensão genderizada sobre os sentidos de violência, medo e risco nas decisões analisadas nos serve como alerta para a produção de pesquisa no campo da Sociologia e da Criminologia, tanto a que desenvolve seus temas em torno da produção do medo nas sociedades contemporâneas quanto a relativa ao funcionamento do sistema de justiça nos casos de violência doméstica.

No primeiro grupo de pesquisa encontramos hegemonicamente uma análise sobre o medo na produção das políticas penais desde o viés analítico das teorias construtivistas e de representação social. Desse modo, o medo é capturado como a produção de representações sociais de insegurança no espaço urbano, catalisador de políticas de restrição de direitos individuais. No entanto, a perspectiva genderizada de medo nos ensina que o enquadramento sobre o medo na cidade obedece também a uma ordem de gênero. O recorte que se apresenta como universal apenas dá conta de uma representação social do medo urbano relativo a crimes contra o patrimônio e crimes contra a vida, mas não se estende à produção do medo em relação às mulheres em seu movimento nas cidades e muito menos à produção nos espaços domésticos (MACHADO, 2014). Esse recorte enviesado (interpretado como universal) não permite, como vimos, que, na análise de alguns juízes, se compreenda a experiência do medo assinalada pelas mulheres.

O medo, nas ciências sociais, compreendido a partir do viés das teorias construtivistas e de representação social, também não permite alcançar a dimensão vivida corporalmente pelas pessoas, e, no caso estudado, pelas mulheres. Segundo as teorias que criticam a prevalência das representações e compreendem de modo não cindido as relações entre natureza 
e cultura, o medo não é apenas uma dimensão imaginária e simbólica, mas também uma dimensão vivida, significada e ressignificada corporalmente (MACHADO, s.d.). As pesquisas sobre a produção do medo precisam dar conta dessa dimensão, levando a sério a expressão do medo produzida e experenciada pelas mulheres, sem colocá-lo como um indicador que, por irracional e emocional, deve ser desconsiderado, seguindo uma ordem cartesiana de divisão entre racional/irracional. Isso também pode impactar as pesquisas no campo do sistema de justiça e, mais especificamente, as pesquisas sobre tecnologias decisórias, especialmente nos casos da LMP.

No segundo grupo de pesquisas, nossos achados também chamam a atenção para que pesquisas que buscam entender o funcionamento do sistema de justiça nos casos de violência doméstica levem em conta as teorias de gênero, compreendendo a posição distinta e desigual dos sujeitos nas relações sociais, bem como a produção de suas preferências em meio a constrangimentos sociais e afetivos, sem o que os seus resultados serão marcados pelo viés de uma ciência que se apresenta como universal e que percebe os sujeitos abstratamente em relação de igualdade e apenas no contexto do espaço público.

Os resultados de perspectiva qualitativa de nossa pesquisa não são parte de uma amostra representacional, mas abrem possibilidades e agendas de discussão sobre o desenvolvimento de tecnologias decisórias que levem em conta as relações de gênero nos casos de violência doméstica (em especial, na produção de decisões sobre MPUs), e, em última análise, sobre o uso adequado de repertórios teóricos que não ocultem a questão de gênero (gender-blindness) nas pesquisas das ciências sociais sobre o sistema de justiça e as políticas penais.

\section{REFERÊNCIAS}

BARDIN, Laurence. Análise de conteúdo. Lisboa: Edições 70, 1977. 118p.

COMTE, Auguste. Discurso preliminar sobre o conjunto do positivismo. Tradução de José Artur Giannotti e Miguel Lemos. São Paulo: Abril Cultural, 1978. (Coleção Os Pensadores).

CONNELL, Raewyn; PEARSE, Rebecca. Gênero: uma perspectiva global. São Paulo: nVersos, 2015.

FERREIRA, Célia; MATOS, Marlene. Violência doméstica e stalking pós-ruptura: dinâmicas, coping e impacto psicossocial na vítima. Psicologia, Lisboa, v. XXVII, n. 2, p. 81-106, 2013. 
GRANGEIA, Helena; MATOS, Marlene. Stalking: consensos e controvérsias. In: MACHADO, C. (coord.). Novos olhares sobre a vitimação criminal: teorias, impacto e intervenção. Braga: Psiquilíbrios, 2010. p. 121-166.

HALL, Doris M. Victims of stalking. In: MELOY, J. Reid (org.). The psychology of stalking: clinical and forensic perspective. San Diego: Academic Press, 1998. p. 115-139.

JORDAN, Carol E.; LOGAN, T.K.; WALKER, Robert; NIGOFF, Amy. Stalking: An examination of the criminal justice response. Journal of InterpersonalViolence, Washington, v. 18, n. 2, p. 148-165, 2003.

KIENLEN, Kristine K. Development and social antecedents of stalking. In: MELOY, J. Reid (org.). The psychology of stalking: clinical and forensic perspective. San Diego: Academic Press, 1998. p. 51-67.

MACHADO, Lia Zanotta. Além das representações: gênero, sexualidade, corpo e violência. Mimeo. [S.d.].

MACHADO, Lia Zanotta. O medo urbano e a violência de gênero. In: MACHADO, Lia Zanotta; MOURA, Cristina Patriota de; BORGES, Antonádia Monteiro (orgs.). A cidade e o medo. Brasília: Verbena e Francis, 2014. p. 103-125.

MATOS, Marlene; GRANGEIA, Helena; FERREIRA, Célia; AZEVEDO, Vanessa. Inquérito de vitimação por stalking: Relatório de investigação. Minho: Grupo de Investigação sobre Stalking em Portugal, 2011. 78p.

MCFARLANE, Judith; CAMPBELL, Jacquelyn C.; WATSON, Kathy. Intimate partner stalking and femicide: urgent implications for women's safety. Behavioral Sciences and the Law, New York, v. 20, p. 51-68, 2002.

MELOY, J. Reid. The psychology of stalking. In: MELOY, J. Reid (org.). The psychology of stalking: clinical and forensic perspective. San Diego: Academic Press, 1998. p. 02-23.

MULLEN, Paul E.; PATHÉ, Michele; PURCELL, Rosemary; STUART, G.W. Study of Stalkers. American Journal of Psychiatry, Washington, v. 156, p. 1.244-1.249, 1999.

MULLEN, Paul E.; PATHÉ, Michele; PURCELL, Rosemary. Stalking: a new categorization of human behavior. In: MULLEN, Paul E.; PATHÉ, Michele; PURCELL, Rosemary (orgs.). Stalkers and their victims. Cambridge: Cambridge University Press, 2000. p. 5-25.

PATHÉ, Michele; MULLEN, Paul E. The impact of stalkers on their victims. British Journal of Psychiatry, Cambridge, v. 170, p. 12-17, 1997. 
PRANDO, Camila Cardoso de Mello. O que veem as mulheres quando o direito as olha? Reflexões sobre as possibilidades e os alcances da intervenção do direito nos casos de violência doméstica. Revista de Estudos Criminais, Porto Alegre, v. 60, p. 115-142, 2016.

ROSENFELD, Barry. Recidivism in stalking and obsessional harassment. Law and Human Behavior, Washington, v. 27, n. 3, p. 251-265, 2003.

ROSENFELD, Barry. Violence risk factors in stalking and obsessional harassment: a review and preliminary meta-analysis. Criminal Justice and Behavior, California, v. 31, n. 1, p. 09-36, 2004.

SAUNDERS, Rhonda. The legal perspectives on stalking. In: MELOY, J. Reid (org.). The psychology of stalking: clinical and forensic perspective. San Diego: Academic Press, 1998. p. 28-51.

TJADEN, Patricia;THOENNES, Nancy. Stalking in America: findings from the National Violence Against Women Survey. U.S. Department of Justice: Washington, DC, 1998.

WALKER, Lenore E.; MELOY, J. Reid. Stalking and domestic violence. In: MELOY, J. Reid (org.). The psychology of stalking: clinical and forensic perspective. San Diego: Academic Press, 1998. p. 140-164.

WALKLATE, Sandra. Gender, crime and criminal justice. Devon:Willan Publishing, 2004. 237p.

ZONA, Michael A.; PALAREA, Russell E.; LANE, John C. Psychiatric diagnosis and the offender Victim typology of stalking. In: MELOY, J. Reid (org.). The psychology of stalking: clinical and forensic perspective. San Diego: Academic Press, 1998. p. 69-84.

\section{COMO CITAR ESTE ARTIGO:}

PRANDO, Camila Cardoso de Mello; BORGES, Maria Paula Benjamim. Concepções genderizadas na análise de deferimento das Medidas Protetivas de Urgência (MPUs). Revista Direito GV, v. 16, n. 1, jan./abr. 2020, e1939. doi: http://dx.doi.org/10.1590/23176172201939.

\section{Camila Cardoso de Mello Prando}

Doutora e Mestre em Direito pela Universidade Federal de Santa Catarina (UFSC). Professora de Criminologia e Direito Penal dos Cursos de Graduação e Pós-Graduação em Direito DA Universidade de Brasília (UnB). CoORdenadora do Centro de Estudos de Desigualdade e Discriminação (CEDD).

camilaprandolgmail.com

\section{Maria Paula Benjamim Borges}

Graduada em Direito pela Universidade de Brasília (UnB).

Advogada.

mariapaulabborgesagmail.com 